\title{
FEI and National Geographic STEM Outreach - Mysteries of the Unseen World
}

\author{
John Williams ${ }^{1}$
}

${ }^{1 .}$ FEI, 5350 NE Dawson Creek Drive, Hillsboro, OR 97124

FEI has partnered with National Geographic on the 3D giant-screen film, Mysteries of the Unseen World. National Geographic is one of the world's largest scientific and educational non-profits with an audience of over 400 million consumers. The goal of Mysteries is inspire curiosity about all things around us that are not visible to the human eye, and in doing so create interest in Science, Technology, Engineering and Math (STEM). Mysteries explores all things that are too fast, too slow, or too small be seen with the human eye. FEI is using Mysteries as a mechanism for STEM outreach to introduce the concepts of the nanoscale, potential applications of nanotechnology, and the uses of electron microscopy.

Since its debut in November of 2013, Mysteries has been viewed by over 800,000 consumers at leading museums and science centers around the world. In addition, National Geographic has an extensive educational outreach network to deploy scientific concepts of the film into the classroom. To date, National Geographic has conducted 11 educator workshops, reaching over 750 educators and more than 15,000 students. An additional 13,000 educator DVD's have been distributed by theaters and at events.

FEI uses Mysteries as the foundation of its STEM outreach efforts. We introduce students to the science and beauty of life and materials at the nanoscale and the tremendous capability of electron microscopy in revealing and in some cases creating this beauty. FEI is continuing to partner with National Geographic and with leading museums to integrate electron microscopy into their STEM education outreach programs. FEI has promoted the film and the associated microscopy themes through hosted events, interactive kiosks at museums, engagements at major STEM exhibitions such as the USASEF, and through development and deployment of an electron-microscopy-based iPad app. In 2014, FEI reached over one million consumers through Mysteries-related outreach. 


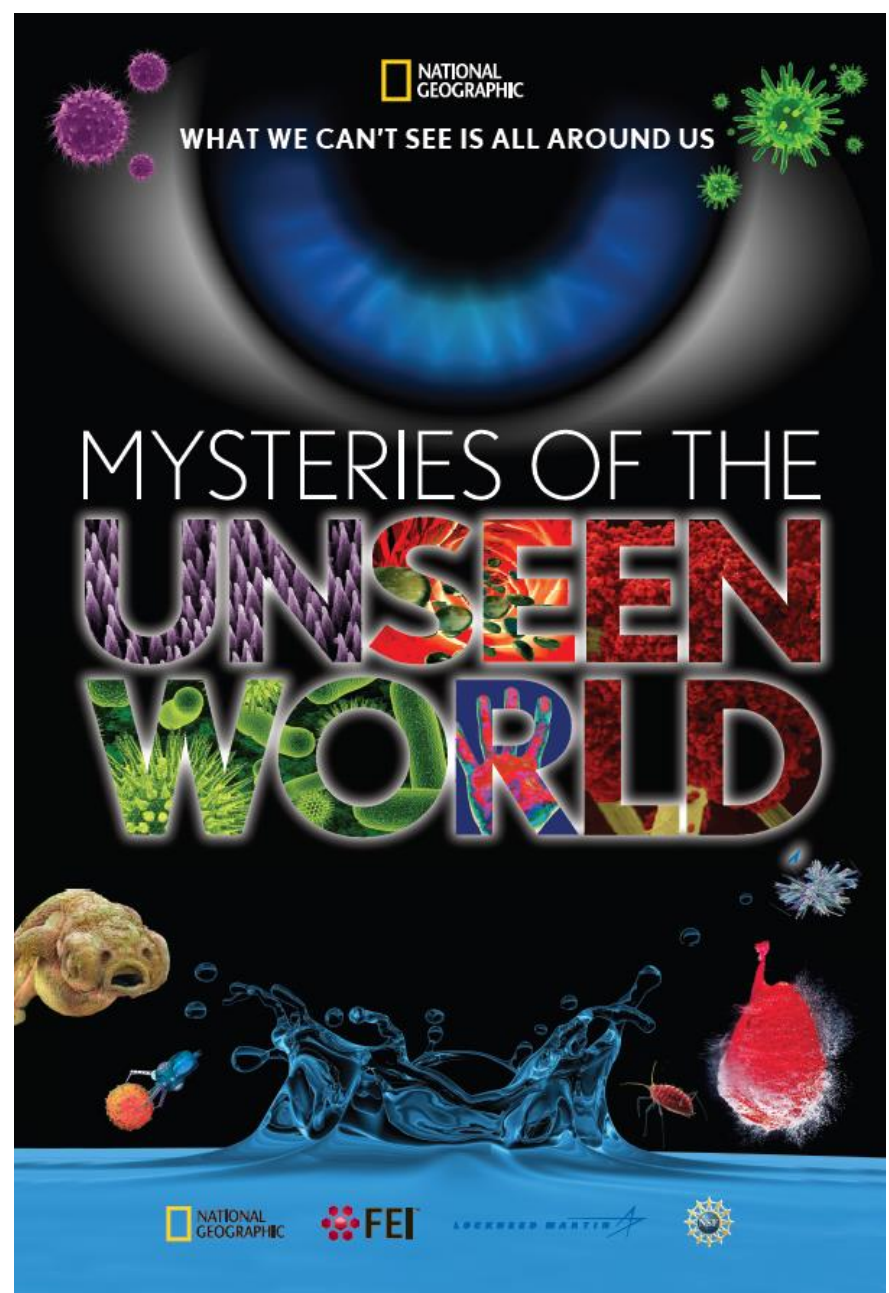

Figure 1. Mysteries of the Unseen World promotional poster

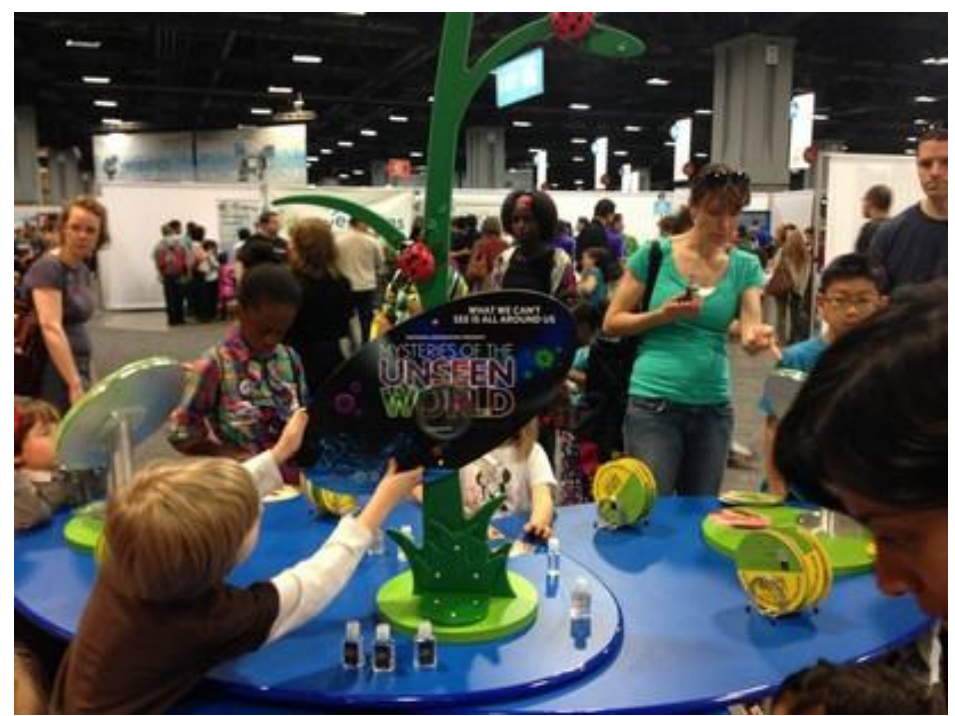

Figure 2. Students at USASEF learning about electron microscopy via the interactive kiosk 